УДК 330.1

DOI: $10.14451 / 1.202 .60$

ББК 65.05

\title{
КОНЦЕПТУАЛЬНЫЕ ОСОБЕННОСТИ ПРОЦЕССА РАЗРАБОТКИ СТРАТЕГИИ УПРАВЛЕНИЯ ПЕРСОНАЛОМ КАК КЛЮЧЕВОЙ ФУНКЦИОНАЛЬНОЙ СТРАТЕГИИ ОРГАНИЗАЦИИ
}

\author{
(c) 2021 Александров Игорь Николаевич \\ кандидат экономических наук, доцент \\ Санкт-Петербургский политехнический университет Петра Великого, Россия, Санкт-Петербург \\ E-mail: a7830298@gmail.com
}

\begin{abstract}
(c) 2021 Гриднева Мария Алексеевна
кандидат экономических наук, доцент

E-mail: mash-v@yandex.ru
\end{abstract}

(C) 2021 Петров Максим Александрович

кандидат социологических наук, доцент

E-mail: petrov_maxim@rambler.ru

(C) 2021 Молодькова Элеонора Борисовна

кандидат социологических наук, доцент

E-mail: eleonor036@yandex.ru

Санкт-Петербургский государственный экономический университет, Россия, Санкт-Петербург

В настоящей статье анализируются концептуальные особенности процесса разработки стратегии управления персоналом как ключевой функциональной стратегии организации. Определены базовые условия формирования HR-стратегии в контексте доминирующих организационных отношений, а также факторы, определяющие её отличительные особенности. Компаративный анализ базовых конкурентных стратегий организации позволил определить основные направления процесса разработки стратегии управления персоналом с учётом концептуальных подходов, факторов внешней и внутренней среды организации. Формулируется авторское видение процесса формирования стратегии управления персоналом в международных компаниях в условиях глобализации и усиления международной конкуренции. Делается вывод о целесообразности использования комбинированной стратегии в подобных условиях.

Ключевые слова: стратегическое управление человеческими ресурсами, HR-стратегия, процесс разработки HR-стратегии, всеохватывающие стратегии управления персоналом, конкретные стратегии управления персоналом.

Актуальность исследования обусловлена тем, что персонал современной организации является одним из важнейших ресурсов, который может обеспечивать компании конкурентное преимущество. Главной целью любой коммерческий организации является выживание в условиях постоянного, часто неблагоприятного, изменения внешней и внутренней среды. Стратегическое управление персоналом направленно именно на её достижение. В то же время недостаточный уровень развития человеческих ресурсов не позволит организации максимально эффективно использовать такие материальные и нематериальные активы, как современное оборудование, передовые технологии или деловую репутацию.
Общая стратегия призвана обеспечить неуязвимость компании в условия турбулентной внешней среды. Она всегда включает в себя несколько основных составляющих. Обычно к ним относят: Стратегию развития, Стратегию управления персоналом, Маркетинговую, Финансовую, Производственную стратегии. Кроме того, в практике стратегического управления помимо вышеперечисленных, отдельно выделяют инновационную стратегию, стратегию НИОКР, инвестиционную стратегию и другие, значимые для тех или иных организаций, функциональные стратегии.

При всей важности перечисленных составляющих общей стратегии организации, часто именно стратегия управления персоналом яв- 
ляется ключевой для выживания и развития организации. Это обусловлено тем, что персонал является основным ресурсом, определяющим успех деятельности всей организации. Именно поэтому, начиная с 70-х годов 20 века, стратегия управления персоналом начинает рассматриваться исследователями как основа определяющая эффективность деятельности всей системы стратегического управления.

\section{Классификация стратегий управления персоналом}

Вопрос классификации стратегий управления персоналом достаточно дискуссионный. Разными исследователями предлагаются различные варианты типизации стратегий управления персоналом. Если взять исследование Майкла Армстронга и Стивена Тэйлора [1], то ими предлагается два основных типа данных стратегий:

1) Всеохватывающие стратегии управления персоналом (ВСУП);

2) Конкретные стратегии управления персоналом, касающиеся различных аспектов управления человеческими ресурсами (КСУП).

Всеохватывающие стратегии описывают общие планы компании, направленные на управление персоналом. Такая стратегия в общих чертах может отвечать на следующие вопросы:

- в каких человеческих ресурсах нуждается организация?

- какие действия организация должна предпринимать для обеспечения бизнеса необходимыми человеческими ресурсами?

- что необходимо делать для привлечения персонала?

- как развивать человеческие ресурсы организации?

- как планируется удерживать персонал?

- на чём должна строиться система мотивации организации?

Конкретные стратегии управления персоналом определяют то, что организация намерена делать в значимых областях [2, 3]. Таким образом, могут формулироваться такие стратегии как:

- Стратегия привлечения наиболее ценных и перспективных сотрудников;

- Стратегия постоянного улучшения качества персонала;

- Стратегия текущего кадрового обеспечения;

- Стратегия управление знаниями персонала;

- Стратегия обучения и развития персонала;

- Стратегия взаимоотношений с сотрудниками;

- Стратегия мотивации и стимулирования персонала и др.

В таблице 1 приведено описание основных характеристик указанных стратегий.

\section{Таблица 1. Типы стратегий управления персоналом}

\begin{tabular}{|l|l|}
\hline \multicolumn{1}{|c|}{$\begin{array}{l}\text { Тип стратегии управления } \\
\text { персоналом }\end{array}$} & \multicolumn{1}{|c|}{ Содержание стратегии } \\
\hline $\begin{array}{l}\text { Стратегия привлечения наибо- } \\
\text { лее ценных и перспективных } \\
\text { сотрудников }\end{array}$ & $\begin{array}{l}\text { Стратегия призвана обеспечить организацию наиболее ценными и пер- } \\
\text { спективными сотрудниками с учётом того, что за них будет идти конку- } \\
\text { рентная борьба с другими работодателями }\end{array}$ \\
\hline $\begin{array}{l}\text { Стратегия постоянного улучше- } \\
\text { ния качества персонала }\end{array}$ & $\begin{array}{l}\text { Стратегия призвана определить перечень направлений улучшения каче- } \\
\text { ства персонала, составить план обеспечения целенаправленной и непре- } \\
\text { рывной работы в данных направлениях }\end{array}$ \\
\hline $\begin{array}{l}\text { Стратегия текущего кадрового } \\
\text { обеспечения }\end{array}$ & $\begin{array}{l}\text { Стратегия призвана обеспечить привлечение и удержание сотрудников с } \\
\text { необхддимым набором компетенций }\end{array}$ \\
\hline $\begin{array}{l}\text { Стратегия управление знаниями } \\
\text { персонала }\end{array}$ & $\begin{array}{l}\text { Стратегия направлена на создание, выявление, обмен и эффективное } \\
\text { использование знаний сотрудников для достижения организационных } \\
\text { целей }\end{array}$ \\
\hline $\begin{array}{l}\text { Стратегия обучения и развития } \\
\text { персонала }\end{array}$ & $\begin{array}{l}\text { Стратегия призвана обеспечить условия и сформировать среду, способ- } \\
\text { ствующую обучению и развитию сотрудников. Стратегия может предпо- } \\
\text { лагать создание системы обучения в организации. Развитие трудового } \\
\text { потенциала сотрудников направлено на повышение качества человече- } \\
\text { ского капитала и создание кадрового резерва }\end{array}$ \\
\hline $\begin{array}{l}\text { Стратегия взаимоотношений } \\
\text { с сотрудниками }\end{array}$ & $\begin{array}{l}\text { Стратегия призвана определить, как компания будет строить отношения с } \\
\text { персоналом при разных сценариях изменения внешней среды. В компа- } \\
\text { нии могут сложиться разные модели взаимоотншений сотрудников и } \\
\text { организации (например, «потребительская» или «партнёрская»), которые } \\
\text { требуют разработки соответствующих стратегий Уп }\end{array}$ \\
\hline $\begin{array}{l}\text { Стратегия мотивации и стиму- } \\
\text { лирования персонала }\end{array}$ & $\begin{array}{l}\text { Стратегия призвана обеспечить долговременное воздействие на персонал } \\
\text { в целях поддержания интереса работников к высокопроизводительному } \\
\text { труду }\end{array}$ \\
\hline
\end{tabular}


Как следствие, при определении общей стратегии развития самой организации, избирается конкретная модель всеохватывающей стратегии управления персоналом, которая дополняется конкретными стратегиями управления персоналом (Стратегией обучения и развития, Стратегией управление знаниями персонала и т.д.). С учётом многообразия возможных вариантов стратегий управления персоналом для различных организаций, исследователями были определены несколько важных фундаментальных факторов, оказывающих на данную стратегию основное влияние $[4,5]$. Особенности стратегии управления персоналом определяются следующими основными факторами:

- Существующей в организации моделью взаимодействия сотрудников и компании;

- Предпочтительной стратегией развития;

- Базовой конкурентной стратегией (основной маркетинговой стратегией);

- Степенью международного присутствия компании (международная корпорация, работающая на глобальном рынке или компания ведущая деятельность только на национальном рынке);

- Спецификой функциональных стратегий;

- Текущим состоянием компании с точки зрения жизненного цикла;

- Текущей и ожидаемой ситуацией на рынке;

- Спецификой внешней среды и иными факторами.

Ниже мы рассмотрим некоторые виды возможных стратегий управления персоналом, которые разрабатываются с учётом вышеперечисленных факторов.

Зависимость стратегии управления персоналом от сложившейся модели взаимоотношений сотрудников и организации

Обычно выделяют несколько основных видов отношений (сотрудников и компании), складывающихся в организации [6]:

- Потребительская модель отношений;

- Партнёрская модель отношений;

- Идентификационная модель отношений.

В таблице 2 приведено их описание и описание характерных для данных моделей стратегий

Таблица 2. Зависимость стратегии управления персоналом от сложившейся модели взаимоотношений сотрудников и организации

\begin{tabular}{|c|c|c|}
\hline $\begin{array}{c}\text { Модель взаимоотношений } \\
\text { сотрудников и организации }\end{array}$ & Отличительные черты модели & $\begin{array}{c}\text { Особенности стратегии } \\
\text { управления персоналом }\end{array}$ \\
\hline Потребительская модель & $\begin{array}{l}\text { Данная модель взаимоотношений } \\
\text { предполагает, что организация и со- } \\
\text { трудники не разделяют общие ценно- } \\
\text { сти и имеют принципально разные } \\
\text { цели. При этом организация и сотруд- } \\
\text { ники могут иметь взаимные инте- } \\
\text { ресы. Сотрудники в данной модели } \\
\text { максимально используют возможно- } \\
\text { сти организации (получают зарплату, } \\
\text { бесплатное образование, опыт работы, } \\
\text { льготы и т.п.), но при изменении } \\
\text { условий (например, при появлении } \\
\text { альтернативного места работы) со- } \\
\text { трудники компанию покидают. }\end{array}$ & $\begin{array}{l}\text { Организация максимально «выжи- } \\
\text { мает» сотрудника. Считается, что } \\
\text { характерными последствиями данной } \\
\text { стратегии является низкий уровень } \\
\text { взаимной ответственности между } \\
\text { персоналом и организацией. Данная } \\
\text { стратегия не будет в долгосрочной } \\
\text { перспективе увеличивать конкурент- } \\
\text { ные преимущества компании. }\end{array}$ \\
\hline Партнёрская модель & $\begin{array}{l}\text { Данная модель взаимоотношений } \\
\text { предполагает, что у работников } \\
\text { формируются партнёрские отноше- } \\
\text { ния, выраженные в значительном } \\
\text { совпадении целей и ценностей. При } \\
\text { партнёрской стратегии организация } \\
\text { может сталкиваться с высокой теку- } \\
\text { честью персонала. Например, сотруд- } \\
\text { ники могут перестать соответствовать } \\
\text { требованиям и их увольняют. Возмож- } \\
\text { на также ситуация, когда потенциал } \\
\text { сотрудника выше, чем занимаемая } \\
\text { должность и отсутствует возможность } \\
\text { роста. }\end{array}$ & $\begin{array}{l}\text { При этой стратегии менеджеры } \\
\text { стремятся развивать сотрудников для } \\
\text { обеспечения потребностей органи- } \\
\text { зации. Сотрудники стремятся увели- } \\
\text { чивать свой трудовой вклад в дея- } \\
\text { тельность фирмы. Кадровая политика } \\
\text { достаточно рациональна, проявляется } \\
\text { в развитии потенциала творческих и } \\
\text { наиболее приверженных организации } \\
\text { сотрудников. }\end{array}$ \\
\hline $\begin{array}{l}\text { Идентификационная } \\
\text { модель }\end{array}$ & $\begin{array}{l}\text { При данной модели отношения стро- } \\
\text { ятся на основе совместного видения } \\
\text { целей и ценностей. }\end{array}$ & $\begin{array}{l}\text { При идентификационной стратегии } \\
\text { кадровая ситуация достаточно ста- } \\
\text { бильна. Состав компании гармонизи- } \\
\text { рован и сбалансирован. }\end{array}$ \\
\hline
\end{tabular}


управления персоналом.

Нужно отметить, что самой негативной по последствиям для организации, может быть ситуация, при которой сотрудники и организация имеют деструктивный характер взаимных отношений. Когда сотрудники и организация настроены относительно друг друга враждебно, они могут намеренно подрывать как репутацию фирмы, так и репутацию работников.

Зависимость стратегии управления персоналом от выбранной Базовой конкурентной стратегии компании

Базовая конкурентная стратегия концептуально определяет то, как организация будет строить отношения с клиентами и, соответственно, какие будут предъявляться требования к персоналу [7]. Майкл Портер определяет следующие Базовые конкурентные стратегии [8]:

- Стратегия лидерства за счёт экономии на издержках;

- Стратегия диверсификации;

- Стратегия фокусирования при низких издержках;

- Стратегия фокусированной диверсификации.

В таблице 3 предлагаются варианты стратегии управления персоналом исходя из выбранной Базовой конкурентной стратегии.

Знаменитый экономист Питер Друкер, писал, что по-настоящему многонациональная компания «требует от своих менеджеров, чтобы в мире, где по-прежнему бушуют национальные страсти, они мыслили и поступали как международные бизнесмены» [9].

В основе стратегии управления персоналом международных компаний должен учитываться фактор реального необратимого изменения мира в результате глобализации [10]. Важно отметить, что одной из причин значительного количества неудачных международных слияний и поглощений является недостаточное внимание к потенциальным проблемам управления многонациональным персоналом при разработке общей стратегии. Проблемы, связанные с существенными организационными изменениями (к которым можно отнести сделки по слиянию или поглощению), в первую очередь отражаются на персонале и соответственно, могут вызывать явное или скрытое сопротивление сотрудников. В стратегии управления персоналом международной компании должны быть отражены следующие основные вопросы:

1. Основные принципы ведения бизнеса международными корпорациями;

2. Общие универсальные принципы управления, применимые как для одной страны, так и в международном масштабе;

3. Специфические виды кадровой работы,

Таблица 3. Вид стратегии управления персоналом в зависимости от выбранной Базовой конкурентной стратегии организации

\begin{tabular}{|l|l|}
\hline $\begin{array}{l}\text { Базовая конкурентная стратегия } \\
\text { организации }\end{array}$ & \multicolumn{1}{|c|}{ Вид стратегии управления персоналом } \\
\hline БКС Лидерство по издержкам & $\begin{array}{l}\text { Tак как одна из наших целей обеспечить низкую себестоимость (в том } \\
\text { числе, низкие издержки на персонал), то в данной ситуции стратегия } \\
\text { управления персоналом должна быть направлена на привлечение сотруд- } \\
\text { ников с достаточными, но не избыточными компетенциями, по прием- } \\
\text { лемой стоимости. Менеджеры должны обладать компетенциями админи- } \\
\text { стратора. }\end{array}$ \\
\hline БКС Дифференциции & $\begin{array}{l}\text { Так как при выборе данной БКС, одна из наших целей обеспечить от- } \\
\text { личительные преимущества нашего продукта, то стратегия управления } \\
\text { персоналом должна быть направлена на привлечение высококвалифи- } \\
\text { цированных сотрудников. Менеджеры должны быть инициативными и } \\
\text { творческими. }\end{array}$ \\
\hline $\begin{array}{l}\text { БКС Фокусирования при низких } \\
\text { издержках }\end{array}$ & $\begin{array}{l}\text { При выборе данной БКС, с учётом фокусирования на конкретный сегмент } \\
\text { рынка, одной из наших целей является обеспечение низкой себестоимо- } \\
\text { сти продукции. Стратегия управления персоналом в этом случае должна } \\
\text { быть направлена на привлечение сотрудников (иногда узкоспециали- } \\
\text { зированных) с достаточными, но не избыточными компетенциями по } \\
\text { приемлемой стоимости. }\end{array}$ \\
\hline $\begin{array}{l}\text { БКС Фокусированной диффе- } \\
\text { ренциции }\end{array}$ & $\begin{array}{l}\text { БКС Фокусированная дифференциация предполагает, что организация } \\
\text { создаёт уникальные продукты в одном или нескольких рыночных сегмен- } \\
\text { тах. Для этого компания должна обладать инициативными, творческими } \\
\text { сотрудниками и менеджерами с высоким уровнем компетенций. Страте- } \\
\text { гия управления персоналом в таком случае должна обеспечивать привле- } \\
\text { чение, развитие и удержания ключевых сотрудников. }\end{array}$ \\
\hline
\end{tabular}


применимые для конкретных стран и регионов;

4. Учёт интересов сотрудников в разных странах;

5. Принципы отбора кандидатов на управление зарубежными подразделениями.

Практика показывает, что в основном транснациональные корпорации используют комбинированную стратегию. В качестве основных выводов, необходимо отметит, что именно стратегия управления персоналом является ключе- вой для выживания и развития организации. Это обусловлено тем, что персонал является основным ресурсом, определяющим успех деятельности всей организации. Планирование процессов развития, сбережения человеческого капитала, учёт способностей, возможностей, профессиональных и личных интересов сотрудников, а также коллективных интересов, в целях выживания и развития организации, должно быть отражено в стратегии управления персоналом.

\section{Библиографический список}

1. Армстронг M. Практика управления человеческими ресурсами: учебник для слушателей, обучающихся по программе «Мастер делового администрирования» / Майкл Армстронг, Стивен Тейлор. - 14-е изд.- СПб.: Питер, 2018. - 1038 с.

2. Кибанов, А. Я. Концепции стратегии кадровой политики организации / А. Я. Кибанов, М. В. Ушакова.- Текст: электронный // Кадровик. Кадровый менеджмент. - 2008. - № 10. - С. 4-10.

3. Калмыкова, О.Ю. Факторы повышения производительности труда в организации / О.Ю.Калмыкова, А. В. Гагаринский // Вестник Самарского государственного технического университета. Серия: Экономические науки. - 2013. - № 2(8). - С. 37-46.

4. Дуракова, И.Б. Управление персоналом: учебник / И.Б.Дуракова, Л.П.Волкова, Е.Н.Кобцева; под ред. И. Б. Дураковой.- М.: ИНФРА-М, 2019. - 570 с.

5. Егоршин, А.П. Основы управления персоналом: учебное пособие / А.П.Егоршин.- 4-е изд., перераб. и доп.-М.: ИНФРА-М, 2020.- 352 с. - (Высшее образование: Бакалавриат). - www.dx.doi.org/10.12737/1685

6. Александров, И. Н. Оценка интеллектуального капитала через призму экономического потенциала организации / И.Н. Александров // Проблемы современной экономики. - 2016. - № 3(59). - С. 65-67.

7. Петров М.А. Теоретические аспекты организационного построения процессов разработки стратегии // Государственное управление и экономика: современное состояние и перспективы развития: материалы международной научно-практической конференции - СПб.: Северо-Западный институт повышения квалификации ФНС России, 2016.- С. 291-301.

8. Портер М. Международная конкуренция / Пер. с англ.- М.: Международные отношения, 1993. - 896 с.

9. Друкер П. Задачи менеджмента в XXI веке / Пер. с англ.-М.: Изд. дом «Вильямс», 2004. - 272 с.

10. Петров А.Н., Сулейманкадиева А.Э., ХореваЛ.В., Петров М.А., Монахова Ю.Д. Стратегическое управление сетевыми структурами: новый подход к оценке совместимости партнёров в сетевых альянсах // Экономика, предпринимательство и право.-2020.- Том 10._№ 6.- С. 1621-1634. DOI: 10.18334/epp.10.6.110421 